\title{
Alan Turing: Founder of Computer Science
}

\author{
Jonathan P. Bowen \\ Division of Computer Science and Informatics \\ School of Engineering \\ London South Bank University \\ Borough Road, London SE1 0AA, UK \\ Museophile Limited, Oxford, UK \\ jonathan.bowen@lsbu.ac.uk \\ http://www. jpbowen.com
}

\begin{abstract}
In this paper, a biographical overview of Alan Turing, the 20th century mathematician, philosopher and early computer scientist, is presented. Turing has a rightful claim to the title of 'Father of modern computing'. He laid the theoretical groundwork for a universal machine that models a computer in its most general form before World War II. During the war, Turing was instrumental in developing and influencing practical computing devices that have been said to have shortened the war by up to two years by decoding encrypted enemy messages that were generally believed to be unbreakable. After the war, he was involved with the design and programming of early computers. He also wrote foundational papers in the areas of what are now known as Artificial Intelligence (AI) and mathematical biology shortly before his untimely death. The paper also considers Turing's subsequent influence, both scientifically and culturally.
\end{abstract}

\section{Prologue}

Alan Mathison Turing [8]23 33] was born in London, England, on 23 June 1912. Educated at Sherborne School in Dorset, southern England, and at King's College, Cambridge, he graduated in 1934 with a degree in mathematics. Twenty years later, after a short but exceptional career, he died on 7 June 1954 in mysterious circumstances. He is lauded by mathematicians, philosophers, and computer sciences, as well as increasingly the public in general.

Unlike some theorists, Turing was willing to be involved with practical aspects and was as happy to wield a soldering iron as he was to wrestle with a mathematical problem, normally from a unique angle. With hindsight, Turing's 1936 seminal paper on computable numbers foretold the capabilities of the modern computer. World War II (1939-45) then brought about a radical, but perhaps fortuitous, change of direction in Turing's career, as his unique mathematical abilities were recognized during his time at Cambridge and he was invited to join Bletchley Park, the centre of the United Kingdom's efforts to break German secret codes. Decryption was laborious to do by hand in the time needed and Turing recognized that machines, together with great human ingenuity, could tackle the problem far more quickly and reliably. 
In 1999, Time magazine listed Turing among the 20th century's one hundred greatest minds [47], along with the DNA discoverers Crick and Watson, the physicist Albert Einstein, Alexander Fleming, the discoverer of penicillin, and the flying pioneers, the Wright brothers. Turing's achievements during his short lifetime were extensive. Best known as the genius who broke Germany's most secret codes during the Second World War, Turing was also the founding 'father of computer science' [5|8|9|. A search of "father of computer science" and "Alan Turing" together on Google gives over 57,000 results. Today, all who use information technology are familiar with the impact of his original ideas [17|18].

Turing proposed the insightful innovation of storing applications, and the other programs necessary for computers to perform for us, inside the computer's memory, ready to be opened whenever desired. At a time when the term 'computer' meant nothing more than a human clerk who sat at a desk doing calculations by hand, Turing envisaged a 'universal computing machine' [48] whose function could easily be transformed from acting as a word processor, to a desk calculator, to an automated chess opponent - or to anything else that can be formulated as an algorithmic software program. Like many significant ideas, this now seems as obvious as the arch or the wheel, but with this single invention of the stored program universal computer, Turing transformed the world.

In 1945, Turing went on to start the design of a stored-program electronic computer called the Automatic Computing Engine - or ACE. The name was in homage to the 19th-century computing pioneer Charles Babbage who proposed large mechanical calculating 'engines'. Turing's sophisticated ACE design saw wider success later in form of the English Electric Company's DEUCE computer, one of the earliest electronic computers to be available commercially. The DEUCE became an early success for the developing computer industry in the United Kingdom and, together with a small number of other computers, all greatly influenced by Turing's ideas, the DEUCE helped propel the UK into the age of the computer.

Turing also contributed to advances at the University of Manchester, where the engineers Sir Frederic Williams (1911-1977) and his student and then colleague Tom Kilburn (1921-2001) built the first universal Turing machine to be realized in electronic hardware. Their 'Baby', which can be considered as the world's earliest modern computer, first ran in June 1948, the same year that Turing joined the Computing Machine Laboratory at Manchester. He remained there for the rest of his life.

In addition to his exceptional theoretical and practical contributions with respect to the development of the computer, not to mention the new science of computer programming, Turing was the first pioneer of the areas of computing now known as Artificial Intelligence (AI) [52]. He also made important contributions to mathematics, logic, philosophy, theoretical biology, and the study of the mind. Mathematicians, philosophers, and computer scientists all claim Turing as their own as a result. 


\section{Biography}

\subsection{Youth and pre-war}

Alan Turing [22] was the son of an British civil servant who worked in India [33]. In 1912, his parents returned to England for his birth in Maida Vale, west London, at what is now the Colonnade Hotel [55]. At the age of 14, he was sent to Sherborne School, a traditional British public school in Dorset in southern England. In 1926, on crossing the English Channel from France where his family was living at the time, and arriving at Southampton for his first term at school, he found that the General Strike was under way and that no trains were running. He took the initiative and cycled the significant distance from Southampton to Sherborne, staying the night at Blandford Forum on the way (see Figure 1, demonstrating his determination when faced with a practical problem even at this age.

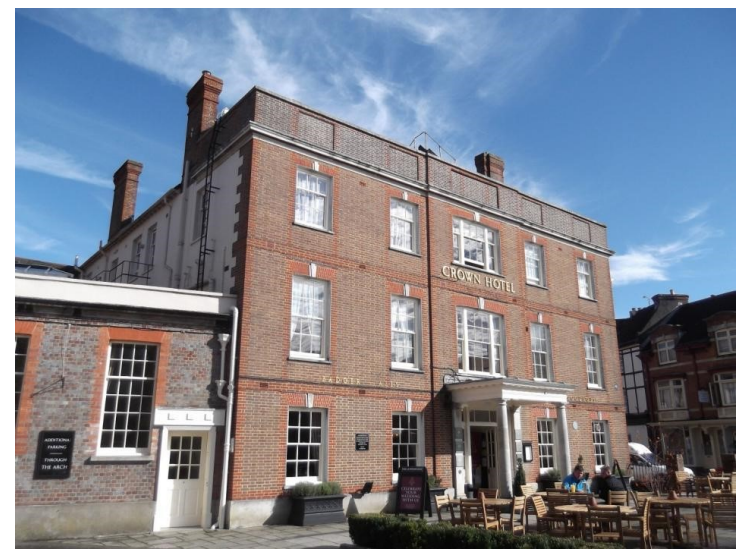

Fig. 1. The Crown hotel at Blandford Forum, Dorset, where Turing stayed during his 1926 cycle ride to Sherborne School. (Photograph by Jonathan Bowen.)

Turing's interest in science was noted by his schoolteachers, but was not particularly encouraged at such a conservative establishment. He was able to solve advanced problems from first principles, for example without having been taught calculus. By the age of 16, he had encountered and understood the work of Albert Einstein (1879-1955). While at school Turing formed a close friendship with a fellow scientifically minded student, Christopher Morcom, who tragically died in 1930 during his last term at Sherborne. This had a traumatic effect on Turing and any religious leanings that Turing may have had were affected, subsequently making him more atheistic in his outlook, but possibly increasing his interest in the working of the mind.

Turing went on to study mathematics at King's College, Cambridge, from 1931 to 1934, graduating with a first-class degree; he was subsequently elected at a remarkably young age to be a Fellow of the College in 1935. At Cambridge, the direction of his 
research was influenced by the lectures of Max Newman (1897-1984), one of his few academic collaborators. In 1936, he submitted his groundbreaking paper on computable numbers [48] that was to form the cornerstone for the rest of his career; this presented the concept of a computing machine, and in particular a 'universal machine' capable of computing a wide class of numbers. Newman recognized the importance of the work and encouraged Turing for much of his subsequent career. Turing's notion of universality was what is thought of as 'programmability' in computers today. As he stated in a paper in the context of a human computer, "a man provided with paper, pencil, and rubber, and subject to strict discipline, is in effect a universal machine" [29[50].

Turing's efforts developed the 1931 research of the German mathematician Kurt Gödel (1906-1978) and have led to the use of the term 'Turing machine' for his universal machine: he demonstrated that any mathematical calculation that can be represented as an algorithm can be performed by such a machine. The Entscheidungsproblem (or 'decision problem') was a mathematical challenge posed by David Hilbert (1862-1943) in 1928 as to whether is there always an algorithm to determine the truth or falsity of a mathematical statement. Turing also demonstrated the insolubility of the problem by first showing that it is impossible to decide algorithmically whether a given Turing machine is satisfactory. This is now known as the halting problem and the issue was a vexing one to mathematicians. Turing machines remain a very important concept in the theory of computation and computability to this day [24].

From 1936 to 1938, Turing studied for a PhD degree at Princeton University in the USA under the American mathematician Alonzo Church (1903-1995), obtaining his doctorate in a remarkably short period [149]. Earlier, they had independently developed the Church-Turing thesis, characterizing the nature of computation and stating that every effectively calculable function produced by any means is also computable using a Turing machine. Although the thesis cannot be proved, it is almost universally accepted by mathematicians and theoretical computer scientists.

Turing later returned to Cambridge and attended lectures by the philosopher Ludwig Wittgenstein (1889-1951) about mathematical foundations. Wittgenstein argued that mathematicians invented (rather than discovered) truth, but Turing disagreed.

\subsection{World War II}

Turing was recruited to Bletchley Park (or 'Station X') [32 [45], after working part-time for the Government Code and Cypher School (now known as the Government Communications Headquarters, or GCHQ). Before World War II, he had already contributed ideas on breaking the German Enigma machine (see Figure 2) for encrypting messages. This meant that within weeks of joining Bletchley Park he had specified a machine that could be used to help decode Enigma messages [46]. This was named the 'bombe' after an earlier and less efficient Polish-designed machine, the 'bomba'.

The bombe worked by taking a piece of probable plain text from the original message (known as a 'crib') and working through combinations of the Enigma machine's rotors and plugboard settings. Most possible settings would quickly produce contradictions, allowing them to be eliminated and leaving only a few combinations to be investigated in greater depth. The machine effectively undertook a mathematical proof 

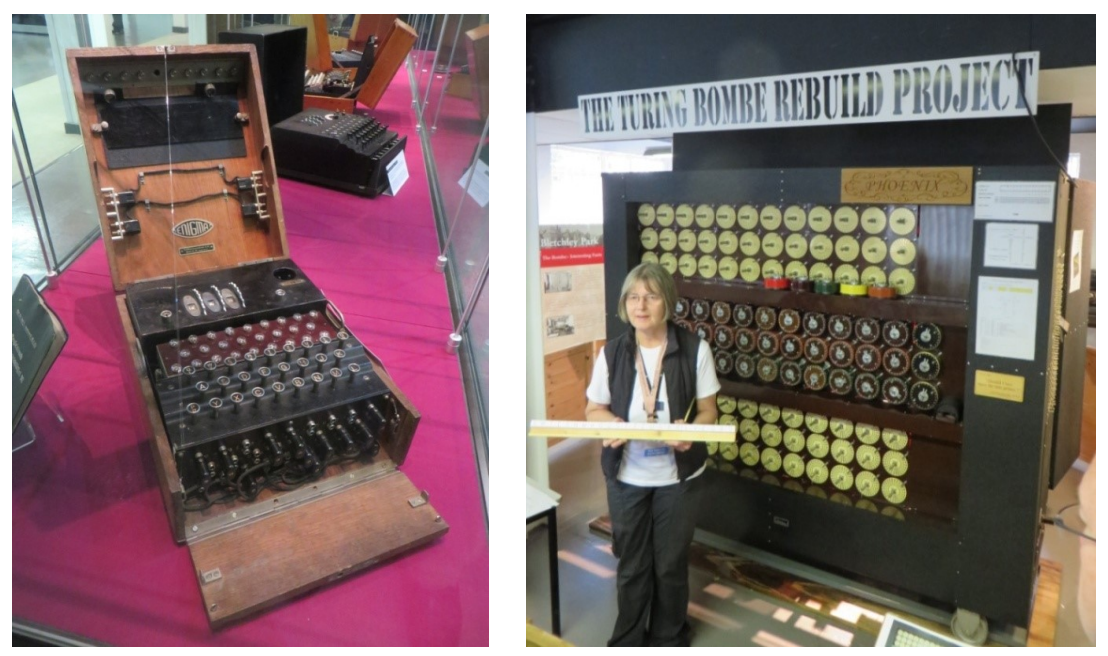

Fig. 2. A German Enigma machine (left) and the Turing Bombe rebuild project (right) at Bletchley Park. (Photographs by Jonathan Bowen.)

mechanically, far more quickly and reliably than a human (or even a team of humans) was able to do so.

Turing chose to work on naval Enigma decryption because, as he said, "no one else was doing anything about it and I could have it to myself". This was typical of Turing, although he collaborated well with others at Bletchley Park. During his time there, he developed a number of novel decryption techniques and devices, which were often given playful slang terms. One of these, developed in 1942, was 'Turingery' or 'Turingismus', a hand technique for finding patterns in the Lorenz cipher wheel cams. It was especially useful because the information remained valid for a significant period.

Some of Turing's eccentricities were evident while he worked at Bletchley Park. He chained his cup to his radiator in his office within the unprepossessing Hut 6 (see Figure 3 to avoid it being lost or stolen. He was also known to wear his gas mask while cycling to work, not because of fear of being gassed, but to avoid hay fever.

Turing was not averse to dealing with administrative issues when necessary. At one point when Turing could not obtain the personnel he needed, he and others at Bletchley Park contacted Winston Churchill about the urgency of the matter. This elicited the response "Action this day" [46] from Churchill, who well understood the importance of the work undertaken at Bletchley Park.

Although not directly involved in its design, Turing's influence on work at Bletchley Park helped in the development of the world's first programmable digital electronic computer there, the Colossus [26], designed by Tommy Flowers (1905-1998). Turing was awarded the OBE (Officer of the Order of the British Empire) in 1945 for his war work, but his actual contribution remained secret for many years afterwards. 


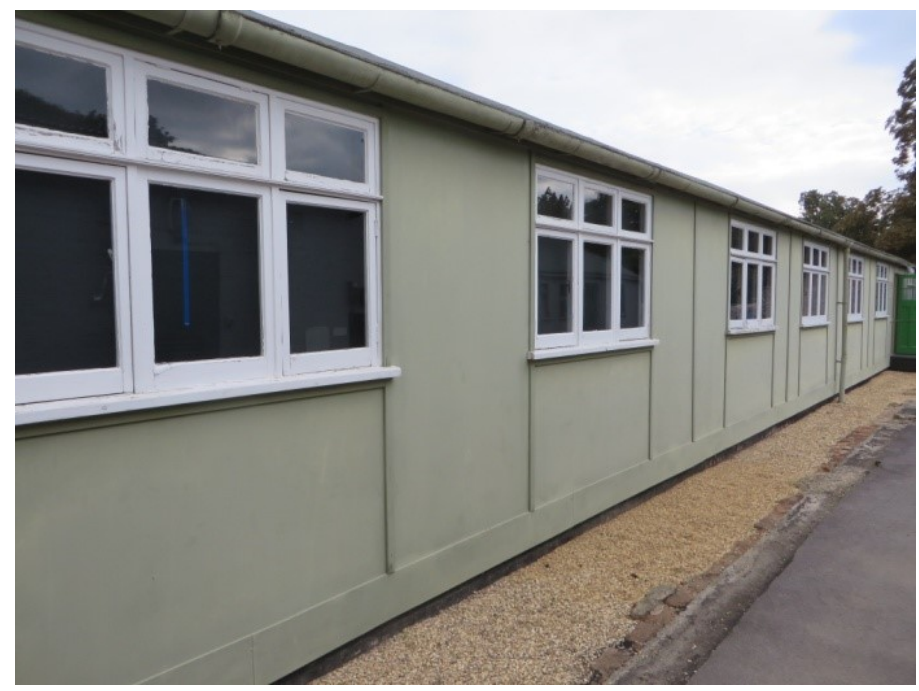

Fig. 3. Hut 6 at Bletchley Park, now restored. (Photograph by Jonathan Bowen.)

\subsection{Post-war}

After World War II, from 1945 to 1947, Turing worked at the National Physical Laboratory (NPL), west of London [57]. Here, influenced by his experience at Bletchley Park, he worked on the design of the very fast Automatic Computing Engine (ACE), an early computer [20[25]. Unfortunately, delays (partly due to bureaucracy) meant that Turing became frustrated with the project, and even the cut-down Pilot ACE was not built until after he left NPL to return to Cambridge for a sabbatical year. Turing never returned to work at NPL.

In 1948, he joined the mathematics department at the University of Manchester, where his earlier mentor from Cambridge, Max Newman, was now based [42]. He was appointed the Deputy Director of the University's computing laboratory, working on software for the Manchester Mark 1 'Baby', an early stored-program computer [37]. Turing worked on software for the Mark 1 and even produced what may have been the first proof of correctness for a program [51]. Although this had little influence at the time, its importance in the field of formal methods [6]15] was realised much later [1141].

In 1950, Turing published a seminal paper on the subject of machine intelligence, later known as Artificial Intelligence, in the journal Mind [52]. He devised what became known as the 'Turing test' to provide a possible demonstration of machine intelligence. To pass the test, a computing machine must appear human when interacting with a person in such a way that it is indistinguishable from a real human being. Such a feat has still not been achieved fully, although it is deemed to be a viable aim and remains relevant to this day. There are now many variants for the test. 
Towards the end of his life until his early and inadequately explained death in 1954, Turing worked in the interdisciplinary area of mathematical biology - and specifically, morphogenesis, the process that allows organisms to generate their shape. In 1952, he published a paper, The chemical basis of morphogenesis [53], which demonstrated that simple mathematical equations can produce complex patterns; this paper has subsequently been very influential as a foundational work in the field of computational biology, but much of his work in this area was not published until his Collected Papers appeared much later [19].

\section{Influence}

\subsection{Coined terms}

Turing's name is associated with a significant number of different concepts coined by others and related directly or indirectly to his original ideas. Many can be found on Wikipedia [56]. Two of the most well-known are Turing's abstract concept of a computing device, now known as a 'Turing machine', and his idea of a test for machine intelligence in comparison with a human, the 'Turing test'. There are also more specialized versions of these concepts, such as a 'symmetric Turing machine', the 'reverse Turing test' where a human attempts to mimic being a computer, and a 'visual Turing test' for computer vision systems.

The 'Church-Turing thesis' (aka 'Turing's thesis') is a hypothesis about computable functions named after mathematician and Turings $\mathrm{PhD}$ supervisor Turing himself. The idea was conceived separately and using different approaches by both of them in the 1930s. Later in 1985, David Deutsch formulated a stronger physical version of the Church-Turing thesis, the 'Church-Turing-Deutsch principle' [28].

In computability theory, 'Turing reduction' is an algorithm that transforms one problem into another problem using a function that is computable by an oracle machine, a Turing machine connected to an 'oracle' that is able to provide a solution for a given computational problem. 'Turing equivalence' means that the reduction is possible in both directions. 'Turing computability' is the main form of computability used in recursion theory. The 'Turing degree', or degree of unsolvability of a set of natural numbers, gives a measure for the level of the set's algorithmic unsolvability.

The term 'Turing tarpit' (or tar-pit) was coined by the American computer scientist Alan Perlis (1922-1990) in 1982. It is a term for a computer interface or programming language that is flexible in the facilities provided, but is hard to learn in general due to the lack of support for its more widely used features.

There is even a programming language named 'Turing', developed in 1982 as a teaching language in the standard imperative programming style. Further related languages include 'Turing+', introduced in 1987 for programming concurrent systems, and 'Object-Oriented Turing', developed in 1991 as a replacement for Turing+, providing object-oriented programming features.

Recently, the term 'Alan Turing law' entered general use to describe United Kingdom legislation proposed in 2016 for an amnesty law to pardon homosexual men retrospectively [2]. This passed into UK law in 2017 [3]. 


\subsection{Online resources}

There is a significant amount of material relating to Turing that is accessible online. Some of the leading websites in this regard include [10]:

- Alan Turing: The Enigma (http://www.turing.org.uk) [12], maintained by Turing's definitive biographer, Andrew Hodges [33];

- The Turing Digital Archive (http://www.turingarchive.org), provided by Turing's college, King's College, Cambridge, with nearly 3,000 images;

- The Turing Archive for the History of Computing (http: / / www . a lanturing. net), digital facsimiles by Jack Copeland, a leading Turing scholar [19[21], and Diane Proudfoot, from Canterbury Christ Church University in New Zealand;

- The Alan Turing Year (http: //www. turingcentenary . eu), celebrating Turing's 2012 centenary of his birth, with various events around the world [18].

Google Scholar (http://scholar.google.com) provides information about academic publications written by researchers around the world, including an entry for Turing [30] (see Figure 4). Turing's three most cited papers have been foundational for three important fields of study.

\begin{tabular}{|c|c|c|}
\hline Title $\quad 1-20$ & Cited by & Year \\
\hline $\begin{array}{l}\text { The chemical basis of morphogenesis } \\
\text { AM Turing } \\
\text { Bulletin of Mathematical Biology } 52 \text { (1), 153-197 }\end{array}$ & 9966 * & 1952 \\
\hline $\begin{array}{l}\text { On computable numbers, with an application to the Entscheidungsproblem } \\
\text { AM Turing } \\
\text { Proceedings of the London Mathematical Society } 42 \text { (2), 230-265 Theoretical computer }\end{array}$ & cience & 1936 \\
\hline $\begin{array}{l}\text { Computing machinery and intelligence } \\
\text { AM Turing } \\
\text { Mind } 59 \text { (236), } 433-460\end{array}$ & 9095 & 1950 \\
\hline $\begin{array}{l}\text { Systems of logic based on ordinals } \\
\text { AM Turing } \\
\text { Proceedings of the London Mathematical Society } 2 \text { (1), 161-228 }\end{array}$ & 973 & 1939 \\
\hline $\begin{array}{l}\text { Intelligent machinery } \\
\text { AM Turing } \\
\text { The Essential Turing, 395-432 }\end{array}$ & 916 * & 1948 \\
\hline $\begin{array}{l}\text { Computing machinery and intelligence } \\
\text { AM Turing } \\
\text { Computers \& Thought, } 11-35\end{array}$ & 665 & 1995 \\
\hline $\begin{array}{l}\text { Rounding-off errors in matrix processes } \\
\text { AM Turing } \\
\text { The Quarterly Journal of Mechanics and Applied Mathematics 1 (1), 287-308 }\end{array}$ & 621 & 1948 \\
\hline $\begin{array}{l}\text { Computability and } \lambda \text {-definability } \\
\text { AM Turing } \\
\text { The Journal of Symbolic Logic } 2 \text { (4), 153-163 }\end{array}$ & 534 & 1948 \\
\hline $\begin{array}{l}\text { Checking a large routine } \\
\text { AM Turing } \\
\text { The early British computer conferences, } 70-72\end{array}$ & $488 *$ & 1948 \\
\hline $\begin{array}{l}\text { Digital computers applied to games } \\
\text { AM Turing, MA Bates, BV Bowden, C Strachey } \\
\text { Faster than thought } 101\end{array}$ & 397 & 1953 \\
\hline
\end{tabular}

Fig. 4. Alan Turing's most cited papers on Google Scholar [30]. 
Google Scholar also presents the number of citations per year for a given author. Citations to Turing's work have grown exponentially over the years in general, with relatively few still at the time of the Hodges biography in 1983 [33] and far more by the time of his 2012 centenary (see Figure 5). There are now around six citations a day to Turing's work in scientific publications around the world.

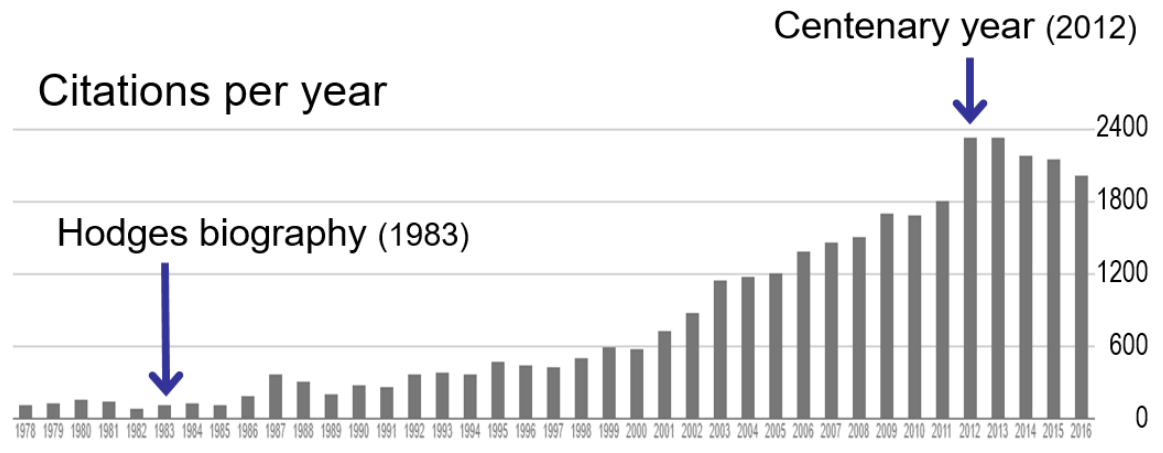

Fig. 5. Citations to Alan Turing's publications by year on Google Scholar [30].

Microsoft Academic Search, generated by a research project at Microsoft Research in Beijing, until recently provided similar facilities to Google Scholar, although with a smaller number of publications that were no longer being updated in recent years. It did however have better graphical visualization presentation of coauthors, citing authors, and transitive coauthorship links between any two authors [10]. It included an entry for Alan Turing. More recently, Microsoft has launched a new facility, Microsoft Academic (http://academic.microsoft.com), with a better corpus of publications but without the same visualization facilities. E.g., for Turing's entry, see [40].

The Mathematics Genealogy Project is a web-based resource providing access to a database (http://genealogy.math.ndsu.nodak.edu) of mathematically related PhD supervisors and their students. Turing's PhD supervisor, the Princeton University mathematician Alonzo Church, has an entry that includes Turing [39]. Turing himself only had one PhD student, the mathematician Robin Gandy (1919-1995) at the University of Cambridge, who was subsequently an academic at the University of Oxford.

\subsection{Cultural influence}

Turing has had a very significant scientific influence historically [7], but his now iconic status has also influenced more mainstream culture too, partly due to his treatment as a homosexual, now considered unjust, and his short life, most likely due to his resulting suicide. In theatre for example, Breaking the Code was a 1986 play by Hugh Whitemore [34], based on Turing's life and specifically the biography by Andrew Hodges [33]. It was performed in London's West End and later in 1988 on Broadway in New York, 
starring the British actor Derek Jacobi in the lead role of Turing on both occasions. In 1996, the play appeared as a BBC television film, also with Jacobi as Turing.

There have been a number of sculptures dedicated to the memory of Alan Turing in the UK and elsewhere. In 2001, a memorial to Turing was installed in Sackville Park, Manchester, where he worked at the end of his life. This is in the form of a bronze sculpture of Turing sitting on a bench and holding an apple. It was widely believed that Turing committed suicide due to biting a cyanide-laced apple. The monument was unveiled on 23 June, Turing's birthday. It was inspired by the play Breaking the Code.

A unique slate sculpture of Turing with an Enigma machine by Stephen Kettle is now on display at Bletchley Park [36]. The slate selected was from North Wales, which Turing visited both as a child and adult. There are other memorial sculptures and busts of Turing around the world. For example, at Southwest University in Chongqing, China, there is a bust outside the computer science department (see Figure 6), along with the American mathematician and computing pioneer John von Neumann (19031957), who was himself influenced by Turing, especially with his concept of the von Neumann machine, a more practical model of the computer than Turing's earlier Turing machine. Even in such a remote location from Turing's home country, his achievements are recognised, especially by computer scientists.

In literature, the 1995 novel Enigma by Robert Harris was inspired by the work of Turing and others at Bletchley Park [31]. The Turing Test by Chris Beckett in 2008 [4], a collection of 14 science fiction genre short stories, won the 2009 Edge Hill Short Fiction Award. The stories, first published between 1991 and 2006, include aspects of Artificial Intelligence and its relationship with humanity.

Turing's centenary in 2012 was celebrated in a number of ways, including an exhibition dedicated to him at the Science Museum in London (see Figure 7). There were also a number of Turing-related meetings at Bletchley Park, Cambridge, Manchester, Oxford, and elsewhere [13[18].

In popular music, the musical duo known as the Pet Shop Boys were inspired by a 2011 UK television documentary on Turing and then the Hodges biography [33] to write the musical work A Man for the Future, based on the life of Alan Turing. This included read passages from the Hodges biography, chosen with the help of Hodges himself. The operatic work, in eight movements, was premiered in a BBC PROM concert at the Royal Albert Hall in London on 29 July 2014, including extensive choral contributions by the BBC Singers, and received a standing ovation.

In film, The Imitation Game of 2014 [35] was an American Hollywood production of a historical drama, loosely based on Turing's life and incorporating much fictional dramatic licence, with Andrew Hodges as a consultant. The film starred the leading film actors Benedict Cumberbatch as Turing and Keira Knightley as Joan Clarke MBE (1917-1996), his fellow cryptanalyst at Bletchley Park, to whom Turing proposed marriage in early 1941.

In art, the Lumen Prize winner Andy Lomas has been inspired by morphogenesis to combine his mathematical, programming, and artistic abilities to produce pseudo-living organisms at the cellular level in 2D, 3D and moving forms [10|38]. There has also been influence of the Turing test on poetry [16]. No doubt Turing's ideas and increasing fame will continue to inspire the arts for the future too. 

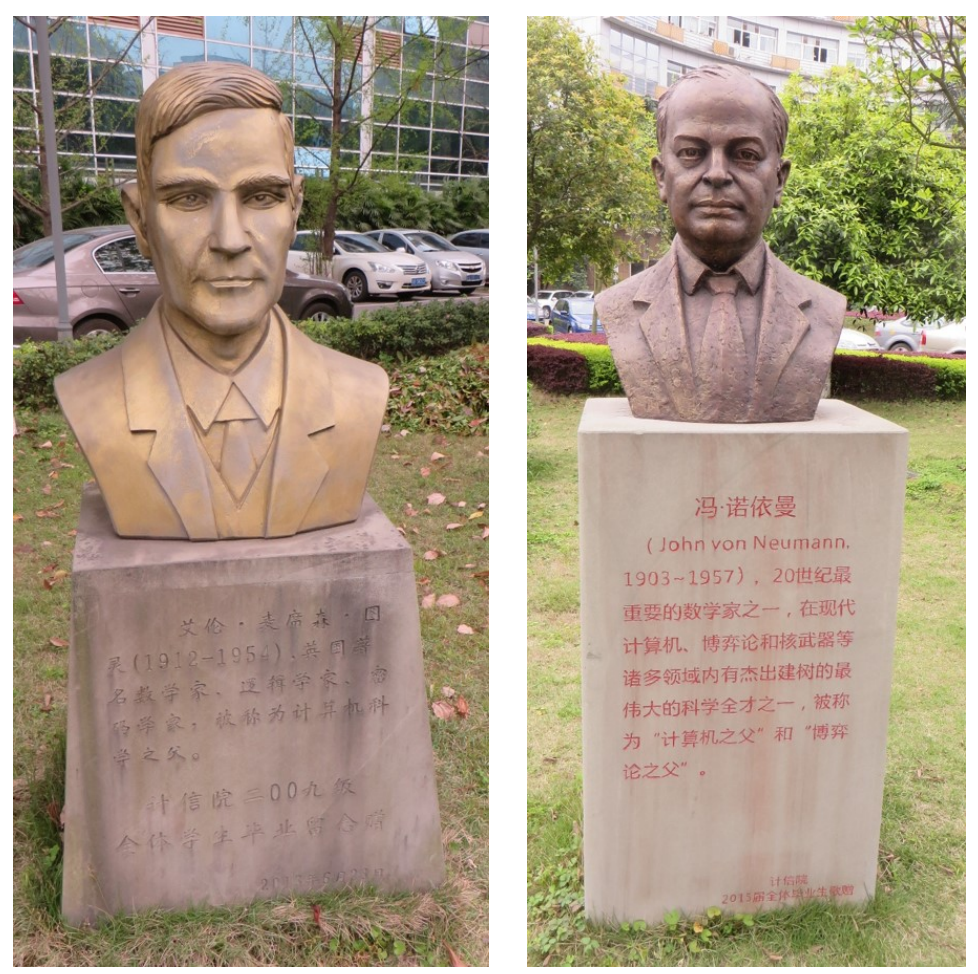

Fig. 6. Busts of Alan Turing (left) and John von Neumann (right) on the campus of Southwest University, Chongqing, China. (Photographs by Jonathan Bowen.)

\section{Epilogue}

Turing was a homosexual at the time when homosexuality was illegal in the United Kingdom. He was charged with gross indecency in 1952, losing his security clearance as a result, and was forced to take female hormones in an attempt to 'cure' him if he wished to avoid imprisonment. On 8 June 1954, his cleaner found him dead at his home in Wilmslow, Cheshire. The cause of death was certainly cyanide poisoning, believed to be from a half-eaten apple found by his bed, but this was never tested. It was determined that he had committed suicide, although it is possible that his death was an accident since he experimented with cyanide at home. A verdict in today's courts would undoubtedly be less decisive from the evidence available [21].

Earlier that year, in a postcard to his friend, the Cambridge and Oxford mathematician Robin Gandy, Turing had written a short poem:

Hyperboloids of wondrous Light;

Rolling for aye through Space and Time;

Harbour those Waves which somehow Might;

Play out God's holy pantomime 


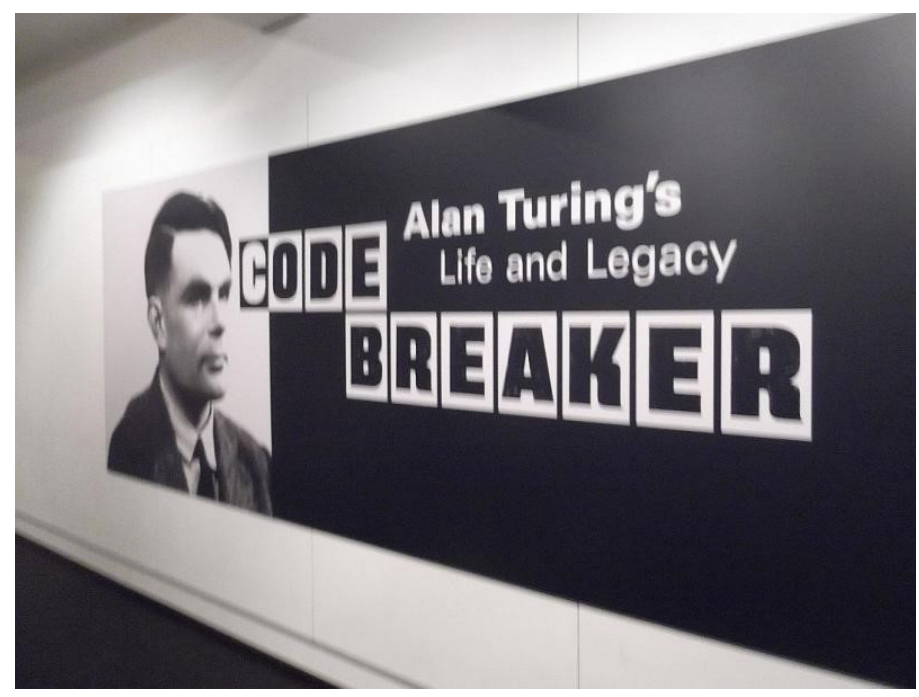

Fig. 7. The entrance of an exhibition on Alan Turing at the Science Museum, London, for his centenary in 2012. (Photograph by Jonathan Bowen.)

- an apposite epitaph for someone who moved from religious belief to disbelief during his lifetime [33]. Geoffrey Jefferson, Professor of Neurosurgery at the University of Manchester, aptly described Turing as "a sort of scientific Shelley" [55|54]. Both Turing and the poet Percy Bysshe Shelley (1792-1822) were somewhat maverick and individualistic geniuses who died before their time.

Turing was elected a Fellow of the Royal Society (FRS) in 1951 [42], an indication of the esteem held for him by scientists in the United Kingdom, but wider recognition of his contributions came long after his death with the development of computer science [27] and as the truth of his crucial wartime role at Bletchley Park began to be revealed [32]. It is notable that Turing's three most cited papers by far (currently around 910,000 citations each on Google Scholar [30]) (see also Figure 4) were published in 1936, 1950, and 1952 [48|52|53]; each of these was foundational in subsequent fields: theoretical computer science, artificial intelligence, and mathematical biology. Given Turing's premature death in 1954, within four year of the publication of two of his three most significant papers, it is very likely that he would have gone on to produce further inspirational work had he lived longer.

The 2012 book The Scientists [43] included Alan Turing as one of the top 43 scientists of all time [8]. Turing is increasingly remembered by the public at large as well as by scientists. There is now a memorial statue in Manchester and a unique slate statue is on view at Bletchley Park, as previously mentioned. There are blue plaques marking his London birthplace, the home where he died in Cheshire, and elsewhere. In 2009, there was even a UK government apology by the Prime Minister, Gordon Brown, for his official treatment, followed by a Royal Pardon by Queen Elizabeth II in 2013 [13]. 
Perhaps most fittingly, the nearest equivalent to the Nobel Prize, given annually to an outstanding computer scientist by computing's international professional body, the Association for Computing Machinery (ACM), is known as the A. M. Turing Award (http://amturing.acm.org). Turing's legacy is explored further in [13]. Despite his untimely death at only 41, Alan Turing's influence will live on in the field of computing, mathematics, and philosophy.

Acknowledgements: Thank you to my good colleague Prof. Zhiming Liu for academic support over the years and financial support provided through Southwest University in Chongqing, China. Thank you as well to my coauthors, Prof. Jack Copeland et al., on The Turing Guide [23|44]. Parts of this paper have been adapted and updated from [8], with permission of the editor, and from a talk at Gresham College in London [9].

\section{References}

1. Appel, A.W. (ed.): Alan Turing's Systems of Logic: The Princeton Thesis. Princeton University Press (2014)

2. BBC: 'Alan Turing law': Thousands of gay men to be pardoned. BBC News (20 Oct 2016), http://www.bbc.co.uk/news/uk-37711518

3. BBC: Thousands of gay men pardoned for past convictions. BBC News (31 Jan 2017), http://www.bbc.co.uk/news/uk-38814338

4. Beckett, C.: The Turing Test. Elastic Press (2008/2012)

5. Bernhard, C.: Turing's Vision: The Birth of Computer Science. MIT Press (2016)

6. Boca, P.P., Bowen, J.P., Siddiqi, J. (eds.): Formal Methods: State of the Art and New Directions. Springer (2010)

7. Bowen, J.P.: A brief history of algebra and computing: An eclectic Oxonian view. IMA Bulletin 31(1/2), 6-9 (1995)

8. Bowen, J.P.: Alan Turing. In: Robinson [43], pp. 270-275

9. Bowen, J.P.: Alan Turing: The founder of computer science. Gresham College (31 Oct 2013), http://www.gresham.ac.uk/lectures-and-events/ alan-turing-the-founder-of-computer-science

10. Bowen, J.P.: Alan Turing: Virtuosity and visualisation. In: Bowen et al. [14], pp. 197-204, http://dx.doi.org/10.14236/ewic/EVA2016.40

11. Bowen, J.P.: The $Z$ notation: Whence the cause and whither the course? In: Liu, Z., Zhang, Z. (eds.) Engineering Trustworthy Software Systems: First International School, SETSS 2014, Chongqing, China, September 8-13, 2014. Lecture Notes in Computer Science, vol. 9506, pp. 104-151. Springer (2016), http://dx.doi.org/10.1007/ 978-3-319-29628-9_3

12. Bowen, J.P., Angus, J., Borda, A., Beler, A., Hodges, A., Filippini-Fantoni, S.: The development of science museum websites: Case studies. In: Hin, L.T.W., Subramaniam, R. (eds.) E-learning and Virtual Science Centers, chap. XVIII, Section 3, Case Studies, pp. 366-392. Idea Group Publishing, Hershey (2005)

13. Bowen, J.P., Copeland, B.J.: Turing's legacy. In: Copeland et al. [23], chap. 42

14. Bowen, J.P., Diprose, G., Lambert, N. (eds.): EVA London 2016: Electronic Visualisation and the Arts. Electronic Workshops in Computing, BCS (2016), http: / /www . bcs . org/ ewic/eva2016

15. Bowen, J.P., Hinchey, M.G.: Formal methods. In: Gonzalez, T.F., Diaz-Herrera, J., Tucker, A.B. (eds.) Computing Handbook, vol. 1, chap. 71, pp. 1-25. CRC Press, 3rd edn. (2014) 
16. Clements, W.: Poetry beyond the Turing Test. In: Bowen et al. [14], pp. 213-219, http: //dx.doi.org/10.14236/ewic/EVA2016.42

17. Cooper, S.B., Hodges, A. (eds.): The Once and Future Turing: Computing the World. Cambridge University Press (2016)

18. Cooper, S.B., van Leeuwen, J. (eds.): Alan Turing: His Work and Impact. Elsevier Science (2013)

19. Copeland, B.J. (ed.): The Essential Turing. Oxford University Press (2004)

20. Copeland, B.J. (ed.): Alan Turing's Automatic Computing Engine: The Master Codebreaker's Struggle to Build the Modern Computer. Oxford University Press (2005)

21. Copeland, B.J.: Turing: Pioneer of the Information Age. Oxford University Press (2012)

22. Copeland, B.J., Bowen, J.P.: Life and work. In: Copeland et al. [23], chap. 1

23. Copeland, B.J., Bowen, J.P., Sprevak, M., Wilson, R.J., et al.: The Turing Guide. Oxford University Press (2017)

24. Copeland, B.J., Posy, C.J., Shagrir, O.: Computability: Turing, Gödel, Church, and Beyond. MIT Press (2013)

25. Copeland, B.J., et al.: Alan Turing's Electronic Brain. Oxford University Press (2005/2012)

26. Copeland, B.J., et al.: Colossus: The Secrets of Bletchley Park's Codebreaking Computers. Oxford University Press (2006)

27. Dasgupta, S.: It Began with Babbage: The Genesis of Computer Science. Oxford University Press (2014)

28. Deutsch, D.: Quantum theory, the Church-Turing principle and the universal quantum computer. Proceedings of the Royal Society pp. 97-117 (1985), http://dx.doi.org/10 . $1098 /$ rspa.1985.0070

29. Evans, C.R., Robertson, A.D.J. (eds.): Key Papers: Cybernetics. Butterworths, London (1968)

30. Google Scholar: Alan Turing. Google (2017), http://scholar.google.com/ citations?user=VWCH lwkAAAAJ

31. Harris, R.: Enigma. Hutchinson (1995)

32. Hinsley, F.H., Stripp, A. (eds.): Code Breakers: The Inside Story of Bletchley Park. Oxford University Press (1993)

33. Hodges, A.: Alan Turing: The Enigma. Simon and Schuster / Princeton University Press (1983/2012)

34. IMDb: Breaking the Code. Internet Movie Database (1996), http://ww.imdb.com/ title/tt0115749

35. IMDb: The Imitation Game. Internet Movie Database (2014), http://imdb.com/ title/tt2084970

36. Kettle, S.: Alan Turing. Stephen Kettle (2012), http://www.stephenkettle.co. uk/turing.html

37. Lavington, S. (ed.): Alan Turing and his Contemporaries: Building the World's First Computers. BCS - The Chartered Institute for IT (2012)

38. Lomas, A.: Species explorer: An interface for artistic exploration of multi-dimensional parameter spaces. In: Bowen et al. [14], pp. 95-102, http://dx.doi.org/10.14236/ ewic/EVA2016.23

39. Mathematics Genealogy Project: Alonzo Church. Department of Mathematics, North Dakota State University (2017), http://genealogy.math.ndsu.nodak.edu/id.php? id $=8011$

40. Microsoft Academic: A. M. Turing. Microsoft (2017), http://academic. microsoft.com/\#/detail/664303655

41. Morris, F.L., Jones, C.B.: An early program proof by Alan Turing. IEEE Annals of the History of Computing 6(2), 139-143 (Apr 1984), http: // dx.doi.org/10.1109/MAHC. 1984.10017 
42. Newman, M.H.A.: Alan Mathison Turing, 1912-1954. Biographical Memoirs of Fellows of the Royal Society 1, 253-263 (Nov 1955), http://dx.doi.org/10.1098/rsbm. 1955.0019

43. Robinson, A. (ed.): The Scientists: An Epic of Discovery. Thames and Hudson (2012)

44. Robinson, A.: All around Turing. New Scientist 3107, $42-43$ (7 Jan 2017)

45. Smith, M.: Station X: The Codebreakers of Bletchley Park. Channel 4 Books (1998)

46. Smith, M., Erskine, R. (eds.): Action this Day: Bletchley Park from the breaking of the Enigma Code to the birth of the modern computer. Bantam Press (2001)

47. Time: The great minds of the century. Time 153(12) (29 Mar 1999), http: / / content . time.com/time/magazine/article/0,9171,990608,00.html

48. Turing, A.M.: On computable numbers with an application to the Entscheidungsproblem. Proceedings of the London Mathematical Society 2(42), 230-265 (1936/7), http: / / dx . doi.org/10.1112/plms/s2-42.1.230

49. Turing, A.M.: Systems of Logic based on Ordinals: A dissertation. PhD thesis, Princeton University, USA (1938)

50. Turing, A.M.: Intelligent machinery: A report. Tech. rep., National Physical Laboratory, UK (1948), http: / / www . alanturing.net/intelligent_machinery also in [29]

51. Turing, A.M.: Checking a large routine. In: Campbell-Kelly, M. (ed.) The early British computer conferences. pp. 70-72. MIT Press, Cambridge, MA (1949/1989)

52. Turing, A.M.: Computing machinery and intelligence. Mind 5(236), 433-460 (Oct 1950), http://dx.doi.org/10.1093/mind/LIX.236.433

53. Turing, A.M.: The chemical basis of morphogenesis. Philosophical Transactions of the Royal Society of London 237(641), 37-72 (1952), http://dx.doi.org/10.1098/rstb. 1952.0012

54. Turing, D.: Prof Alan Turing Decoded. The History Press (2015)

55. Turing, S.: Alan M. Turing. W. Heffer \& Sons / Cambridge University Press (1959/2012)

56. Wikipedia: Category:Alan Turing. Wikipedia (2017), http://en.wikipedia.org/ wiki/Category:Alan_Turing

57. Yates, D.M.: Turing's Legacy: A history of the National Physical Laboratory 1945-1995. Science Museum, London (1997) 